\title{
The Unequal Cycling Boom in Germany
}

\author{
Published in: \\ Journal of Transport Geography \\ Available open access here: \\ https://doi.org/10.1016/i.jtrangeo.2021.103244
}

\author{
Ansgar Hudde \\ University of Cologne \\ Institute of Sociology and Social Psychology (ISS) \\ hudde@wiso.uni-koeln.de
}

- Last modified: November 2021 -

\begin{abstract}
:
Over the last two decades, cycling in Germany has increased by more than $40 \%$. This paper analyses how this overall increase is broken down by group, characterised by residence (rural and smaller towns vs. medium-sized and larger cities) and education (high vs. low). It analyses (1) how the composition of the population changes according to these groups, (2) how cycling behaviour develops within these groups, and (3) how the changes in composition and behaviour shape the overall volume of cycling. Data on mobility behaviour comes from the large-scale, representative German Mobility Panel from 1996 to 2018, and the analytical sample covers information on more than 28,000 persons over approximately 730,000 reported trips. Data on changes in population composition comes from the German Socio-Economic Panel. Results show that the increase in cycling is unbalanced and largely a consequence of highly educated people in cities who now cycle twice as much and whose share of the population has doubled. This reveals that the cycling boom is bypassing important parts of the population, which limits the contribution of cycling to sustainability goals. Furthermore, the uneven evolution of cycling amplifies social inequalities in finances and health. Finally, this paper shows that increased cycling comes not only from changing behaviour within groups, but also from altered population composition. The most impactful compositional shift is the increasing level of education, which will likely continue to boost cycling.
\end{abstract}

\section{Keywords:}

travel behaviour, social inequality, cycling, educational differences, population composition, urban/rural 


\section{Introduction and Background}

Governments around the world promote cycling because it is environmentally sustainable, contributes to liveable and attractive localities, and is an effective tool for individual and public health (Blitz, Busch-Geertsema, \& Lanzendorf, 2020; Garrard, Rissel, Bauman, \& Giles-Corti, 2021; Gehl, 2013; Gössling, Schröder, Späth, \& Freytag, 2016; Götschi, Garrard, \& GilesCorti, 2016; Larsen, 2017; Oja et al., 2011; Pucher, Parkin, \& de Lanversin, 2021). The World Health Organization (WHO) recommends a minimum of 150 minutes of moderate-intensity physical activity per week, and encourages cycling as a simple means to achieving this (Jacob, Munford, Rice, \& Roberts, 2020; Martin, Goryakin, \& Suhrcke, 2014; World Health Organization, 2019).

In light of these benefits of cycling, policy makers are enthusiastic about the observation that cycling is 'booming' in Germany (BMVI, 2019; Prognos AG, 2020). However, this paper reveals that this boom is highly uneven. I analyse cycling behaviour in Germany between 1996 and 2018 and show that the cycling boom is mainly driven by well-educated people in mediumsized and large cities who have changed their cycling behaviour and who account for an increasingly large share of the population. In the 1990s, group differences in cycling were relatively small. Since then, highly educated people in medium-sized and large cities have doubled their bicycle use and now spend two-thirds more time on their bicycles than people in cities with low education, twice as much as people in rural areas with high education, and even three times as much as people in rural areas with low education. The high-cycling group of educated urban dwellers has also doubled in size, which is explained by moderate urbanisation and, most of all, by rapid educational expansion.

Differences in cycling between more urban and more rural areas are a focal point of the scientific community and policy makers alike. Much of cycling research deals with urban areas, and in many spatio-temporal contexts, such as contemporary Denmark (Olafsson, Nielsen, \& Carstensen, 2016), the Netherlands (Schwanen, Dijst, \& Dieleman, 2004), the United States (Buehler, Pucher, \& Bauman, 2020), the United Kingdom (Department for Transport, 2020), and Germany (Nobis, 2019), cycling is higher in urban than in rural areas. Urban areas have a higher density of population and amenities, which means that more relevant destinations can be reached within acceptable cycling limits (Schwanen et al., 2004). Furthermore, in cities, people might opt to cycle instead of drive because of increasingly restricted car parking space (Handy, Heinen, \& Krizek, 2012; Kirschner \& Lanzendorf, 2020). However, these higher 
cycling rates in cities do not necessarily mean that the association between population size and cycling rate is linear. In fact, in many European countries, the cities with the highest cycling rates have a population size between 100,000 and 300,000 inhabitants (Buehler \& Pucher, 2021); and some of the relatively cycling-friendly cities in Northern America fall into that size category (Handy et al., 2012). Compared to very large cities, medium-sized cities benefit from the fact that a greater part of the city is within cyclable distance, commutes tend to be shorter, and traffic tends to be less heavy (Handy et al., 2012; Pucher \& Buehler, 2006).

There are only few studies that examine the link between education and cycling in detail, but the available evidence from the United States (Buehler et al., 2020), the Netherlands (Kroesen \& Handy, 2014; Scheepers et al., 2013), the United Kingdom (Carse, Goodman, Mackett, Panter, \& Ogilvie, 2013; Goodman \& Aldred, 2018), and Germany (Blitz et al., 2020; Buehler, Kuhnimhof, Bauman, \& Eisenmann, 2019; Kreyenfeld \& Konietzka, 2017), as well as from the urban areas of Paris (Brondeel, Pannier, \& Chaix, 2016), Brisbane (Rachele et al., 2015), and Bogota (Parra, Gomez, Pinzon, Brownson, \& Millett, 2018) suggest that people with higher education tend to have better access to cycling infrastructure and tend to cycle more. Note that educational level is a part of socioeconomic status (SES), but different aspects of SES, e.g. education and income, are not interchangeable. They have different and sometimes opposing effects on behaviour, including behaviours concerning health, sustainability, and status signalling (Blitz et al., 2020; Friehe \& Mechtel, 2014; Geyer, Hemström, Peter, \& Vågerö, 2006; Griskevicius, Tybur, \& Van den Bergh, 2010; Huisman, Kunst, \& Mackenbach, 2005; Kroesen \& Handy, 2014; Moav \& Neeman, 2012; Pampel, Krueger, \& Denney, 2010; Spellerberg, 1996). Therefore, one cannot infer the impact of education on cycling from the research on income.

In Germany, only a smaller part of educational differences in cycling is explained by different probabilities of living in cycling-friendly neighbourhoods and cities (Hudde, 2022). Rather, these educational differences might be explained by the social meaning of cycling, groupspecific social norms, and status signalling (Bourdieu, 1984; Frater \& Kingham, 2020; Horton, Rosen, \& Cox, 2016; Hudde, 2022; Steinbach, Green, Datta, \& Edwards, 2011). In tendency, cycling has more positive connotations among highly educated people, where it is considered a voluntary lifestyle choice that is associated with health and environmental friendliness values that are increasing in importance (Brick, Sherman, \& Kim, 2017; Elliott, 2013; Griskevicius et al., 2010; Horton et al., 2016; Kennedy \& Horne, 2019; Steinbach et al., 2011). Meanwhile, among those with lower education, cycling tends to have more negative 
connotations and is more often interpreted as a forced behaviour and a sign of a lack of wealth (Horton et al., 2016; Steinbach et al., 2011). For a more detailed discussion of these arguments and analyses, see Hudde (2022).

To my knowledge, no study analyses time trends in the gradients of cycling by education and location size using representative data. Educational expansion is a far-reaching, global characteristic of modern societies (Breen, 2010; Lutz \& Samir, 2011) that leads to greater mobility in general (Holz-Rau \& Scheiner, 2019) but it is currently not a focal point of research on transport mode choice. However, education influences mobility behaviour and therefore it is relevant to study whether the growth in the share of the population with high education affects the prevalence of cycling.

\section{Material and Methods}

\subsection{Data}

I analyse data on mobility behaviour from the nationally representative German Mobility Panel (MOP), waves 1996-2018 (Ecke, Chlond, Magdolen, Hilgert, \& Vortisch, 2020), in combination with information on population composition by education and residence from the German Socio-Economic Panel (SOEP), Version 36 (Goebel et al., 2019). SOEP is Germany's longest-running and most important multi-topic household survey with high representativeness standards, especially concerning social inequality, and a large sample (Turek \& Leopold, 2021). I apply survey weights and access the data via SOEPremote (a tool to access restricted data remotely) because the information on respondents' residence is not available in the scientific use file (Knies \& Spiess, 2007).

MOP collects information on households, their members, and the trips they take during a sevenday period. Annual surveys are conducted during fall, mainly between mid-September and midNovember. Cycling is highly seasonal, but this period roughly represents the yearly average (Nobis, 2019). The Eastern German regions are only covered by MOP starting in 1999. The main analysis combines data from both regions and, as described in section 4 , I further conduct separate analyses for Eastern and Western Germany. Sampling in the MOP is stratified by type of area, household type, and household car ownership (Buehler et al., 2019). MOP covers a complete sample of 22,663 distinct individuals who participated in 2.1 waves on average (47,408 person-years) and reported an average of 23.9 trips per week or 3.4 trips per day 
$(1,131,374$ reported trips). The unit of analysis is person-years (from now on only called persons or individuals). The sample grew over time. It was relatively small in the first two years (1994: 517 individuals, 1995: 737), fluctuated roughly between 1,000 and 1,500 between 1996 and 2011, and then increased up to almost 2,400 in 2018.

\subsection{Sample Selection}

The waves 1994 and 1995 are dropped because information on city size is not available. In Germany, cycling rates are high among people in education, while senior people might cycle less for health reasons. Therefore, to keep the sample more homogeneous and avoid results heavily driven by students or people with health impairments due to age, I restrict the sample to people of typical working age (25 to 64 years). Individuals with missing information on the relevant variables, transport mode, trip duration or education, were dropped from the analysis (1.2\% of persons). ${ }^{1}$ The overall analytical sample covers 28,846 individuals with 730,074 reported trips.

\subsection{Measures}

Main outcome: minutes of cycling per week. Minutes of cycling per week is a direct measure of the (change in) cycling activity and is proportional to its positive health impact. To avoid results that are excessively driven by outliers, values above 420 minutes ( 1 hour per day) are recoded to 420 minutes.

Grouping by location and education. The education measure is binary and distinguishes whether people have Abitur, a school-leaving certificate that is typically awarded after 12 or 13 years of schooling, or whether respondents have at maximum a lower educational school leaving certificate (Hauptschulabschluss, which is typically awarded after 9 years of schooling; Mittlere Reife, typically awarded after 10 years of schooling; or no school leaving certificate). The German educational system is tracked, i.e. at age 10, pupils are typically divided into one of three different school types; two of them prepare for vocational training (those that lead to Hauptschulabschluss and Mittlere Reife), and one academic track leads to Abitur and prepares for university education (Van de Werfhorst \& Mijs, 2010). Abitur is the typical entry requirement for university and two-thirds or more of Abitur-graduates attend university (Reimer, 2013; Ziefle, 2016). Such a binary distinction is meaningful in the German case (Ziefle, 2016), and allows for an unambiguous and intuitive display and interpretation of results.

\footnotetext{
${ }^{1}$ If individuals had missing information on education in one wave but valid information in another wave, the valid information was taken for all years.
} 
This simple measure is also chosen because information on educational level is limited in MOP data. In the waves before 2013, there is no distinction between people who have a degree from a university (or university of applied sciences) and those that 'only' have the university entrance certificate (Abitur) but no university degree. Therefore, the alternative binary distinction between people with and without a university degree is not possible in the German Mobility Panel. $^{2}$

I use a binary measure to distinguish between people living in medium-sized and larger cities, defined as having at least 100,000 inhabitants, and those that live in smaller towns or villages. For brevity, these places are referred to as city/urban and rural for short. As shown below, a robustness check moves this cut-off value from 100,000 to 50,000 inhabitants.

\subsection{Method}

This paper traces cycling behaviour in aggregate and by subgroup (location and education) over 23 years. Observed cycling patterns in one specific year could be blurred by sampling error or the specific weather condition during one survey period. To account for this, all data are smoothed using local linear smoothing (Fan \& Gijbels, 1996; Gutierrez, Linhart, \& Pitblado, 2003).

Smoothing techniques, such as local linear smoothing, are used to identify trends or other relationships between variables without making strong prior assumptions about the shape of the association (Fan \& Gijbels, 1996). Thus, the aim is to let 'the data themselves determine the functional relationship between the two variables' (Andersen, 2009, p. 68).

Here is a brief, non-technical description of the procedure. For (technical) details see e.g., (Fan \& Gijbels, 1996) and (Gutierrez et al., 2003). To estimate a smoothed value - for example, cycling minutes for the year 2000 - we first define a window around that year, which is the bandwidth of the estimation. In this case, this bandwidth is defined as three years in both directions (1997-2003). The algorithm then runs a weighted linear regression over all observations within this bandwidth. The model is weighted such that observations have greater influence the nearer they are to the year $2000 .^{3}$ The year-variable is centred at the year 2000

\footnotetext{
${ }^{2}$ In addition, there is no consistent information on vocational training. Such information on vocational training would be needed to rank education according to established comparable classifications (e.g. the International Standard Classification of Education, ISCED). Note that similar limitations apply to the other large-scale, nationally representative mobility survey, Mobility in Germany (Hudde, 2022).

${ }^{3}$ The weighting follows the Epanechnikov distribution, which is widely used and is the default in Stata's lpoly-command.
} 
and the model's constant is extracted as the smoothed value for the year 2000. This procedure is repeated for each year: to estimate the value for the year 2001, another weighted regression is run for the observational window 1998 to 2004, and so forth.

The value for the bandwidth (the size of the window around the year) affects the smoothing result: a too small window makes the result too 'wiggly' or noisy, whereas a too large window produces an overly smooth estimate that ignores essential aspects of the underlying curve (Fan \& Gijbels, 1996). A suitable bandwidth is chosen by graphical comparison of the raw data and the smoothed fit (Nichols, 2007). Figure A1 in the appendix compares the chosen bandwidth with a larger and a smaller bandwidth (the bandwidth from the main analyses multiplied by 1.5 and divided by 1.5 ) and demonstrates that the main pattern remains stable.

\section{Results}

\subsection{Change in the Composition of the Population}

Figure 1 and Table 1 show how the composition of the population shifted over time. The most remarkable change is educational expansion, manifested in the constantly growing share of people with high education. Overall, the share of highly educated people has almost doubled from 20.3 to $38.3 \%$ (+88.7\%). From the beginning, residents of medium-sized and larger cities were more often highly educated than those in rural areas and smaller towns, and that gap has stayed constant in relative terms: in the cities, the share of highly educated rose from 26.7 to $49.8 \%(+86.6 \%)$; in the rural areas and smaller towns it rose from 17.3 to $32.5 \%(+88.5 \%)$. At the same time, there was slight urbanisation, as the share of people living in medium-sized and larger cities rose from 32.2 to $33.1 \%$, a rise of 0.9 percentage points or $2.8 \%$.

Consequently, the group of highly educated residents of medium-sized and larger cities has seen the biggest gains, almost doubling (from 8.6 to 16.5\%), and the group of residents of rural areas and smaller towns with lower education has seen the biggest losses, declining by approximately one fifth (from 56.1 to $45.2 \%$ ). 


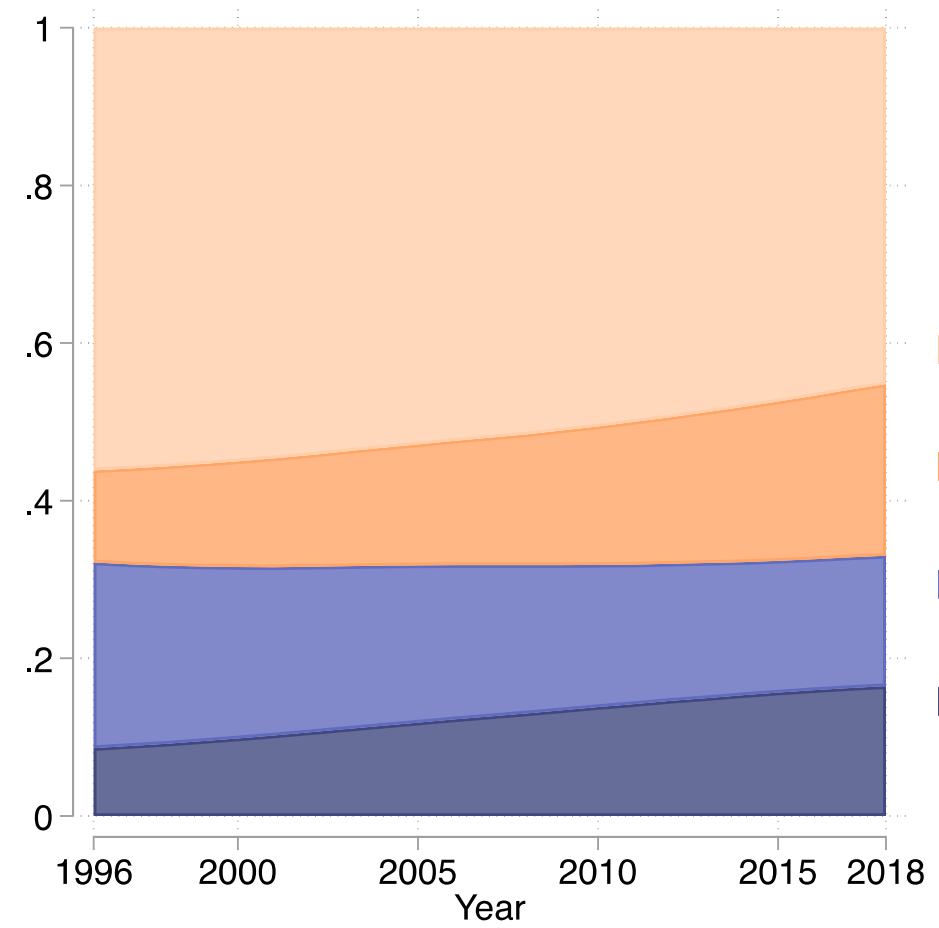

Rural \& smaller towns, low education

Rural \& smaller towns, high education

Medium-sized \& larger cities, low education

Medium-sized \& larger cities, high education

Note:

'Rural \& smaller towns' refers to places with < 100,000 inhabitants;

'Medium-sized \& larger cities' to places with $\geq 100,000$ inhabitants.

Fig 1: Change in the composition of the population. Data is smoothed using local linear smoothing.

Table 1. Composition of the population. Data source: German Socio-Economic Panel (SOEP). Survey weights are applied for the population shares; ' $N$ ' refers to the unweighted sample size.

\begin{tabular}{rrrrrr}
\hline Year & $\begin{array}{r}\text { Medium-sized } \\
\text { \& larger cities, } \\
\text { high education }\end{array}$ & $\begin{array}{r}\text { Medium-sized } \\
\text { \& larger cities, } \\
\text { low education }\end{array}$ & $\begin{array}{r}\text { Rural \& } \\
\text { smaller towns, } \\
\text { high education }\end{array}$ & $\begin{array}{r}\text { Rural \& } \\
\text { smaller towns, } \\
\text { low education }\end{array}$ & $\mathrm{N}$ \\
\hline 1996 & $8.6 \%$ & $23.6 \%$ & $11.7 \%$ & $56.1 \%$ & 8,693 \\
1997 & $8.9 \%$ & $23.1 \%$ & $12.1 \%$ & $55.9 \%$ & 8,596 \\
1998 & $9.2 \%$ & $22.6 \%$ & $12.6 \%$ & $55.6 \%$ & 9,329 \\
1999 & $9.5 \%$ & $22.2 \%$ & $13.0 \%$ & $55.3 \%$ & 9,167 \\
2000 & $9.8 \%$ & $21.8 \%$ & $13.4 \%$ & $55.0 \%$ & 16,304 \\
2001 & $10.2 \%$ & $21.4 \%$ & $13.8 \%$ & $54.6 \%$ & 14,641 \\
2002 & $10.6 \%$ & $21.0 \%$ & $14.2 \%$ & $54.2 \%$ & 15,762 \\
2003 & $11.0 \%$ & $20.6 \%$ & $14.6 \%$ & $53.8 \%$ & 14,633 \\
2004 & $11.5 \%$ & $20.3 \%$ & $15.0 \%$ & $53.3 \%$ & 14,107 \\
2005 & $11.9 \%$ & $19.9 \%$ & $15.4 \%$ & $52.8 \%$ & 13,307 \\
2006 & $12.2 \%$ & $19.6 \%$ & $15.8 \%$ & $52.4 \%$ & 14,054 \\
2007 & $12.6 \%$ & $19.2 \%$ & $16.2 \%$ & $52.0 \%$ & 13,050 \\
2008 & $13.0 \%$ & $18.8 \%$ & $16.6 \%$ & $51.6 \%$ & 12,156 \\
2009 & $13.4 \%$ & $18.4 \%$ & $17.1 \%$ & $51.1 \%$ & 12,652 \\
2010 & $13.8 \%$ & $18.0 \%$ & $17.6 \%$ & $50.6 \%$ & 17,806 \\
2011 & $14.2 \%$ & $17.7 \%$ & $18.1 \%$ & $50.0 \%$ & 18,745 \\
2012 & $14.6 \%$ & $17.4 \%$ & $18.6 \%$ & $49.4 \%$ & 18,064 \\
2013 & $15.0 \%$ & $17.1 \%$ & $19.1 \%$ & $48.8 \%$ & 18,153 \\
2014 & $15.3 \%$ & $16.9 \%$ & $19.7 \%$ & $48.1 \%$ & 15,934 \\
2015 & $15.6 \%$ & $16.7 \%$ & $20.2 \%$ & $47.4 \%$ & 14,973 \\
2016 & $16.0 \%$ & $16.6 \%$ & $20.7 \%$ & $46.7 \%$ & 14,948 \\
2017 & $16.2 \%$ & $16.6 \%$ & $21.3 \%$ & $45.9 \%$ & 17,073 \\
2018 & $16.5 \%$ & $16.6 \%$ & $21.8 \%$ & $45.2 \%$ & 15,794 \\
\hline
\end{tabular}




\subsection{Change in Cycling Behaviour Within Groups}

Before focusing on cycling behaviour, Figure 2 provides an overview of overall mobility patterns and plots the modal split by group for the first and last year of observation. Over time and in all groups, the car is the most widely used means of transport, followed by walking. The car has a higher mode share in the smaller towns and rural areas and, within localities, among those with lower education. The share of walking-trips is higher in medium-sized and larger cities than in smaller towns and rural areas, and there are only relatively small changes over time. A slight tendency is an increase in walking among city residents and a decrease among those with lower education in smaller towns and rural areas. As one would expect, the use of public transport is higher in the cities. Overall, the largest observed shift is the increase in cycling and the decrease in driving among highly educated city residents. This figure also suggests that this increase in cycling has not been at the expense of walking and public transport, but at the expense of the car.

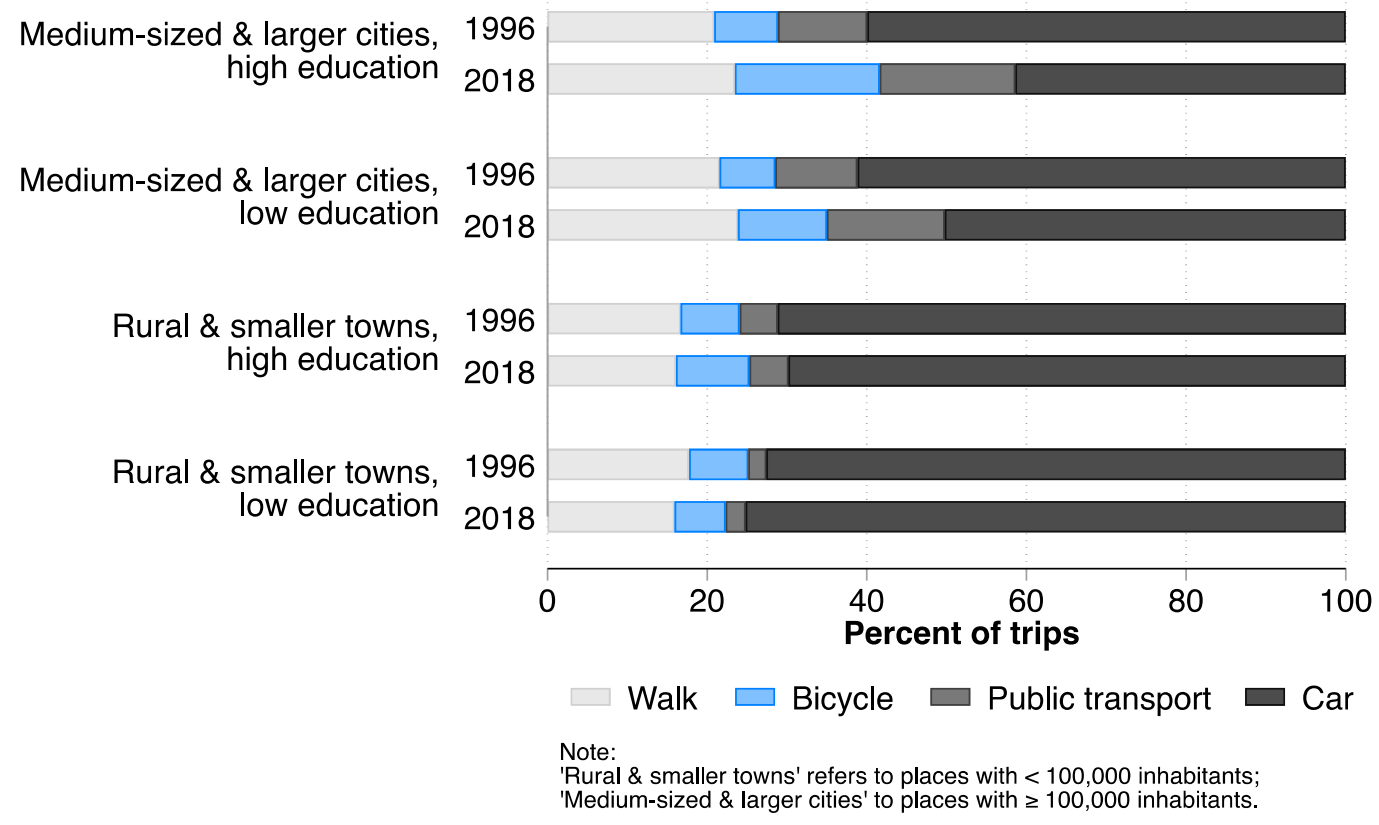

Fig 2: Modal split, by group of residence and education in the first and last year of observation.

Figure 3 shows changes in the average time spent cycling and the share of the population that spends at least 150 minutes per week cycling (see also Table 2). The bold dashed line shows the evolution for all groups combined. Cycling increased considerably: in 1996, people spent an average of 25.9 minutes per week cycling, and in 2018, an average of 36.9 minutes - a rise of $42.5 \%$. 
The figure also breaks down the cycling patterns by the four groups. At the beginning of the observation, there are only moderate differences in cycling - people living in cities and with high education spend around one-third more time cycling than the other groups - but confidence intervals overlap. However, the four groups show markedly different trajectories. Among city residents with high education, cycling increased by 35.0 minutes, which means that it doubled $(+99.4 \%)$. City residents with low education increased their cycling by 16.5 minutes, which represents an increase of almost two-thirds (+63.7\%). Rural residents with high education also increased cycling by 4.8 minutes or $17.7 \%$. There is practically no change among rural residents with low education (+1.0 minutes; $+4.1 \%)$. In 2018 , those in cities and with high education spend almost three times as much time cycling than those in rural areas with low education, more than twice as much as those in rural areas with high education, and two-thirds more than their urban co-residents with low education.
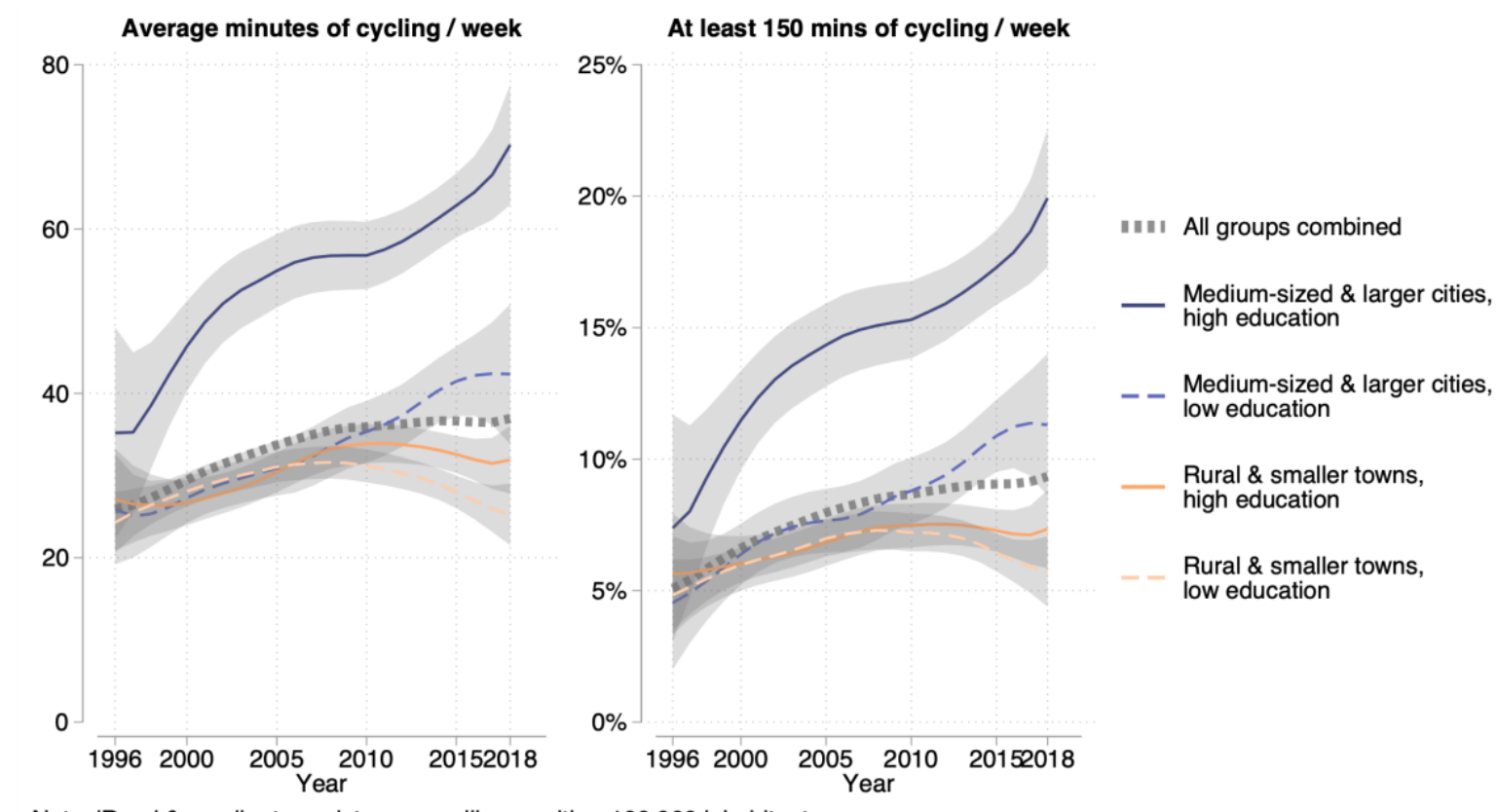

Note: 'Rural \& smaller towns': towns or villages with $<100,000$ inhabitants; 'Medium-sized \& larger cities': $\geq 100,000$ inhabitants.

Fig 3: Change in average minutes of cycling per week, by group of residence and education. Data is smoothed using local linear smoothing. 95\% confidence intervals are displayed. 
Table 2. Average minutes of cycling by years and group. Data source: German Mobility Panel. 'Cycling minutes' refers to the average minutes of cycling per week; 95\%-confidence intervals are displayed in brackets; ' $\mathrm{N}$ ' refers to the unweighted number of observations in the data.

\begin{tabular}{|c|c|c|c|c|c|c|c|c|c|c|}
\hline \multirow[t]{2}{*}{ Year } & \multirow{2}{*}{$\begin{array}{r}\text { All groups } \\
\text { cycling minutes }\end{array}$} & \multirow[b]{2}{*}{$\mathrm{N}$} & \multirow{2}{*}{$\begin{array}{c}\text { Medium-sized \& } \\
\text { larger cities, } \\
\text { high education } \\
\text { cycling minutes }\end{array}$} & \multirow[b]{2}{*}{$\mathrm{N}$} & \multirow{2}{*}{$\begin{array}{c}\text { Medium-sized \& } \\
\text { larger cities, } \\
\text { low education } \\
\text { cycling minutes } \\
\end{array}$} & \multirow{2}{*}{$\mathrm{N}$} & \multicolumn{2}{|c|}{$\begin{array}{l}\text { Rural \& smaller towns, } \\
\text { high education }\end{array}$} & \multicolumn{2}{|c|}{$\begin{array}{l}\text { Rural \& smaller towns, } \\
\text { low education }\end{array}$} \\
\hline & & & & & & & & $\mathrm{N}$ & & $\mathrm{N}$ \\
\hline 13 & $259[231 \cdot 2881$ & 15 & .1] & 96 & $5.9[19.2 ; 32.6]$ & 186 & 3.3] & 198 & 3.0] & \\
\hline & & 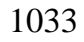 & & 110 & $.1]$ & & & & & \\
\hline 1998 & $.3[25.5 ; 2$ & 994 & $.2]$ & 114 & $9.3]$ & 209 & & 189 & $3.7]$ & 482 \\
\hline 9 & & 2 & 6] & & $.6]$ & 272 & & 244 & & 596 \\
\hline 2000 & $29.5[28.1 ;$ & 1027 & $45.8[40$. & 122 & $27.3[24.2 ; 30.4]$ & 209 & $26.7[24$. & 183 & 28.1 [26.3;29.9] & 513 \\
\hline 2001 & 8] & 286 & .7] & 15 & $.3]$ & 245 & $.8]$ & 247 & .6] & 639 \\
\hline 2002 & & 25 & .7] & 159 & $2.0]$ & 207 & & 217 & & 542 \\
\hline 2003 & 32.2[ & 1278 & $52.6[47$. & 196 & $29.7[26$ & 191 & 0] & 312 & 8] & 579 \\
\hline 2004 & & & $.2]$ & & $.5]$ & 8 & & 296 & & 528 \\
\hline 2005 & & 1123 & $.4]$ & 16 & $30.9[27$ & 177 & & 304 & & 474 \\
\hline 2006 & 3 & 1009 & $.3]$ & 16 & $31.4[27.9$ & 153 & & 265 & 2] & 424 \\
\hline 2007 & 4] & 989 & $.8]$ & 177 & $32.4[28.8$ & 138 & $.0]$ & 280 & $.5]$ & 394 \\
\hline 2008 & $.5[34$. & 886 & $.0]$ & 16 & $33.5[29.8$ & 173 & .7] & 320 & 31. & 424 \\
\hline 2009 & & & $.0]$ & 18 & $346[30 \mathrm{c}$ & 145 & & 271 & & 379 \\
\hline 2010 & $35.9[34$. & 34 & $5.8[52.7 ; 60.9]$ & 208 & $.3[31.6 ; 39.1]$ & 135 & $6.3]$ & 304 & 31.2 & 387 \\
\hline 2011 & & 6 & $57.5[53.5 ; 61.5]$ & 21 & $36.2[32.4 ; 40.0]$ & 11 & & 309 & 30.8 & 381 \\
\hline 2012 & 36 & 1089 & 58.5 & 201 & $37.3[33.5$ & 138 & & 322 & .2] & 428 \\
\hline 2013 & $36.5[35.2 ; 37.8]$ & 1450 & $59.8[56.1 ; 63.6]$ & 304 & $38.9[35.0 ; 42.7]$ & 189 & 5.7] & 418 & 29.7 [27.8;31.6] & 539 \\
\hline 2014 & & & $01.2[2 / .0$ & 32 & $40.4[36$. & 225 & & 505 & & 614 \\
\hline 2015 & $36.6[35.2 ;$ & 1695 & $62.9[59.0 ; 66.8]$ & 354 & $41.5[37.2 ; 45.7]$ & 226 & 4.8] & 520 & 28.0[ & 595 \\
\hline 2016 & $36.5[34.9 ; 38.1]$ & 1762 & $64.5[60.1 ; 68.9]$ & 328 & $42.2[37.3 ; 47.1]$ & 235 & 31.9 [29.4;34.5] & 560 & $27.0[24.7 ; 29.2]$ & 639 \\
\hline 2017 & $36.5[34.4 ; 38.5]$ & 1887 & $66.6[61.1 ; 72.1]$ & נסנ & $42.4[36.1 ; 48.7]$ & 241 & 31.5[ & 583 & $26.0[23.1 ;$ & 678 \\
\hline 2018 & $36.9[34.2 ; 39.7]$ & 1858 & $70.2[63.0 ; 77.5]$ & 440 & $42.4[33.9 ; 50.9]$ & 210 & $31.9[27.8 ; 36.0]$ & 618 & $25.3[21.5 ; 29.0]$ & 590 \\
\hline
\end{tabular}

Two distinct periods can be identified in these time trends. The first goes from 1996 to around 2008, the second from about 2008 to 2018. For all groups combined, the largest part of the increase in cycling happened during the first period (from 25.8 to 35.5 minutes; $+37.6 \%$ ), where cycling increased in all groups, most strongly among the educated city residents $(+61.4 \%$, compared with 22.9 to $30.0 \%$ in the other groups). During the second period, the overall increase in cycling levelled off; it only rose from 35.5 to 36.9 minutes (+4.0\%). The novelty during the second period is that the groups are now showing opposite trends: further major increases among city residents with high $(+23.6 \%)$ and low education $(+26.6 \%)$, but decreases among rural residents with high $(-4.2 \%)$ and low education $(-19.9 \%)$.

How relevant are these changes and differences to individuals and their health, and how many people engage in sufficient levels of physical activity, just by cycling? The WHO recommends a minimum of 150 minutes per week. All groups combined, the share of people that achieve the 150 minutes by cycling alone almost doubled (5.1\% to 9.3\%; right panel of Figure 3). In 1996, there were moderate differences between the groups: $7.4 \%$ of city residents with high education reached the 150 minutes, compared to values between 4.5 and $5.6 \%$ in the other categories. In 
2018, major inequalities emerged: one in five city residents with high education achieves 150 minutes of cycling (19.9\%), compared to around one in twenty rural residents with low education $(5.7 \%)$.

\subsection{Combining Change in the Composition and Change in Behaviour}

Figure 1 shows that the composition of the population has shifted, and Figure 3 shows that group-specific behaviour has changed. Figure 4 brings both together for the years 1996, 2008, and 2018. Each of the bars shows the relative size of the population group (x-axis) and the average cycling behaviour of that group (y-axis). The aggregate area of all four bars represents the total cycling volume and the area of the individual bars the contribution of a population group to the aggregate. Between 1996 and 2008, there is a total increase in cycling volume and an increase in the fraction that city respondents with high education contribute to this total. Compositional changes among the three other groups - fewer people with low, and more people with high education in rural areas - have a minor impact, because these groups show similar behaviour. In sum, the increase during this first period is mainly driven by behavioural changes. The picture is different for the period between 2008 and 2018. The behaviour between groups diverges, and the composition of the population shifts to the benefit of the highest-cycling and to the detriment of the lowest-cycling group, which increases the overall cycling volume.

At all times, highly educated urban residents cycled more than the other groups. However, in 1996, that group comprised a small fraction of the population, and therefore its contribution to the overall cycling intensity was limited. In 1996, the group of highly educated urban residents contributed to $11.6 \%$ of the overall cycling volume. In 2008 , that number was at $20.8 \%$ and in 2018 at $31.4 \%$. These numbers show how group-specific changes in behaviour and educational expansion lead to a vast reshaping in the German cycling landscape. 


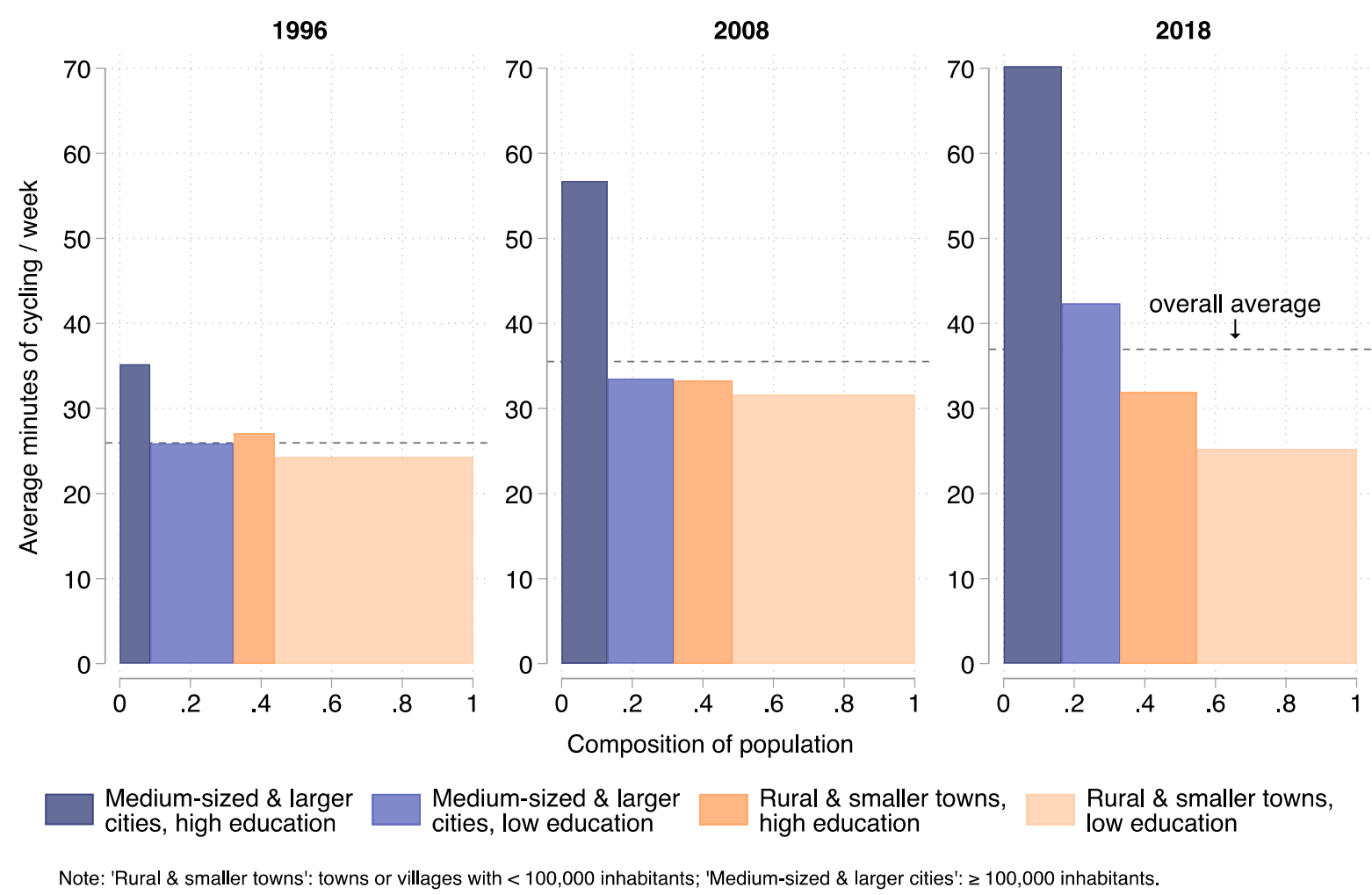

Fig 4: Composition of the population and group-specific cycling behaviour.

To illustrate the relative importance of the changing group composition, here are three what-ifcalculations (Das Gupta, 1993). How would overall cycling have evolved if the group-specific behaviour had changed as observed, but the group size had remained unchanged? Between 1996 and 2018, the average cycling minutes would have increased by $30.9 \%$ (from 25.9 to 33.9 minutes), instead of the observed $42.5 \%$ (from 25.9 to 36.9 minutes). During the first period (1996 to 2008), cycling increased by $36.9 \%$ and, with a constant composition of the population, would have increased by $32.7 \%$. During the second period (2008 to 2018), cycling increased by $4.0 \%$ and would have even slightly decreased by $0.2 \%$ if it was not for compositional change. These figures show that $27 \%(100 \%-30.9 \% / 42.5 \%)$ of the increase in cycling during the entire period, and all of the increase between 2008 and 2018 could only happen because of the shift in the population composition and educational expansion.

\section{Further Analyses and Robustness Checks}

The figures from these further analyses and robustness checks can be found in the online appendix (except for figure 5, which is presented here). 
Cycling patterns within trip distances. The conclusions and implications from these analyses would be different if the divergence in cycling by population groups were only explained by people's trip distances, and not by changes in their decision-making. Therefore, I further analyse the groups' cycling behaviour within trip distances. I compare four distance categories: (a) below $1.5 \mathrm{~km}$, (b) 1.5 to $4.9 \mathrm{~km}$, (c) 5 to $9.9 \mathrm{~km}$, and (d) 10 to $15 \mathrm{~km}$. Together, these distance groups account for more than $80 \%$ of all trips taken.

Figure 5 plots these analyses. Results for all trip distances of at least $1.5 \mathrm{~km}$ are similar to the main results from this article, as described in section 3.2. For trips below $1.5 \mathrm{~km}$, where walking is the most common means of transport, the groups show relatively similar cycling levels and trends. Interestingly, cycling among those with high education living in medium-sized and larger cities has particularly increased for trip distances between 5 and $15 \mathrm{~km}$ over the last ten years. In the three higher categories, those with high education living in medium-sized and larger cities are now 2.5 to 4 times more likely to cycle than those with lower education in smaller towns and rural areas. Overall, these results show that the divergence in cycling behaviour also holds when analysing changes within given trip distances.
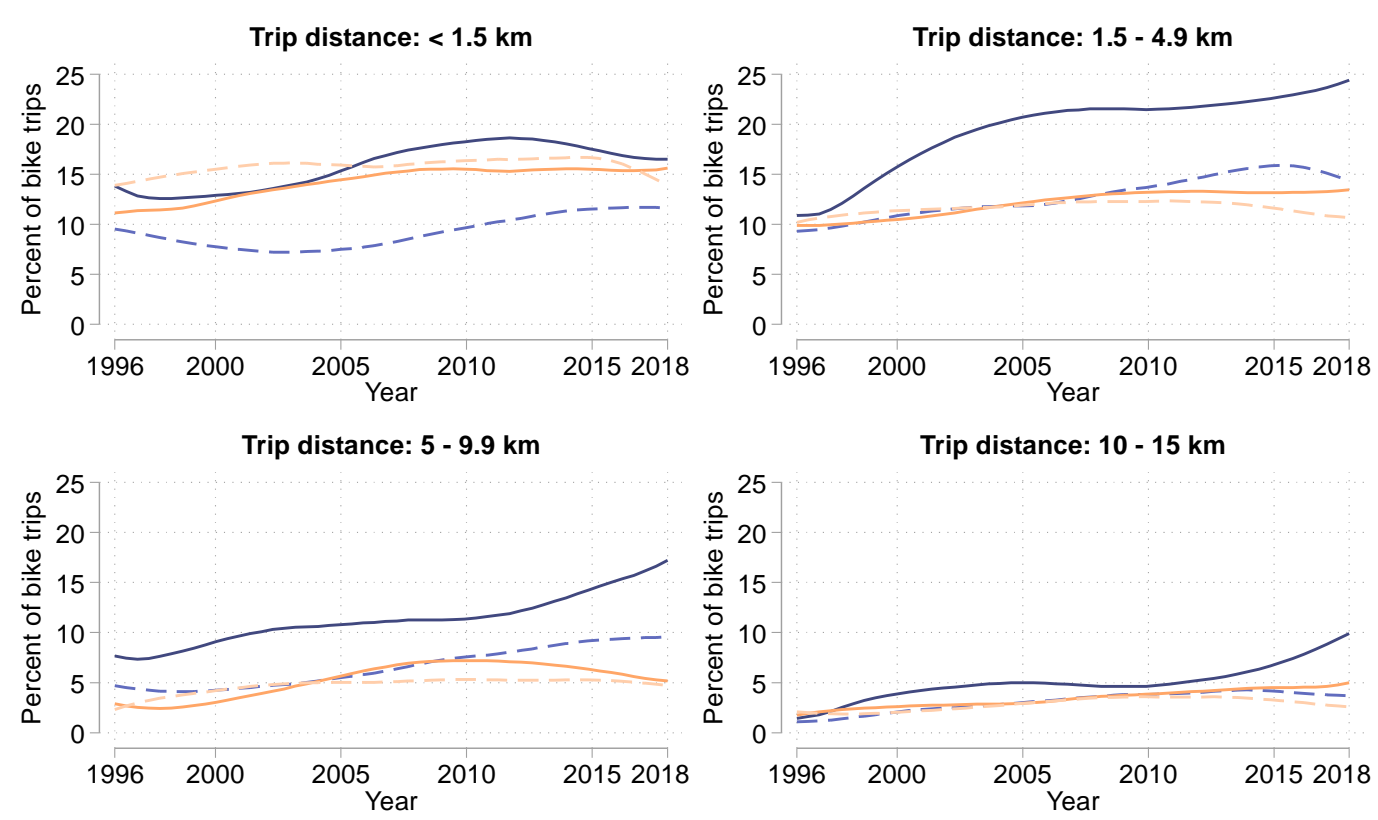

$$
\begin{aligned}
& \text { All groups combined } \quad-\begin{array}{l}
\text { Medium-sized \& larger } \\
\text { cities, high education }
\end{array}-\begin{array}{l}
\text { Medium-sized \& larger } \\
\text { cities, low education }
\end{array} \\
& \begin{array}{ll}
\begin{array}{l}
\text { Rural \& smaller towns, } \\
\text { high education }
\end{array} & --\begin{array}{l}
\text { Rural \& smaller towns, } \\
\text { low education }
\end{array}
\end{array}
\end{aligned}
$$

Note: 'Rural \& smaller towns': towns or villages with < 100,000 inhabitants; 'Medium-sized \& larger cities': $\geq 100,000$ inhabitants

Fig 5: Group-specific cycling behaviour, by trip distance. 
Different cut-off value for city size. Cities with a population between 50,000 and 100,000 are diverse in their degree of urbanity and mobility behaviour. Therefore, I perform a robustness check that moves the cut-off value to distinguish between 'medium-sized and larger cities' and 'smaller towns and rural areas' from 100,000 to 50,000 inhabitants. Empirically, cycling behaviour in cities with 50,000 to 100,000 inhabitants lies between the behaviour in smaller and larger places. With this change, the broader results of growing behavioural gaps by residence and education remain unchanged. When looking at this re-categorisation in more detail, the urban-rural divide is already visible in 1996 and the decline in cycling among those with low education in the smaller towns and rural areas shows even more drastically.

Adjusting for changes in the gender- and age-composition. The age- and gender-composition of the location- and education-groups have changed over time (see Table A1 in the Online Appendix) and these changes may confound observed behavioural trends in the groups (Aldred, Woodcock, \& Goodman, 2016). Gender and age affect the likelihood of being highly educated and living in a large city; and these variables could also affect cycling behaviour (even though previous findings from Germany suggest little difference in cycling by age and gender groups, (Buehler \& Pucher, 2021; Goel et al., 2021; Nobis, 2019). To rule out that this paper's key findings are simply driven by such compositional changes, I conduct analyses in which gender and age are held constant over time within education and location groups.

Here are the three technical steps of this procedure. First, I run linear regression models that control for gender and age. These models are run separately for the four location- and educationgroups, and age enters with dummy variables for ten-year age groups. Second, to attain the ageand gender-adjusted values, I compute predicted values of cycling minutes for the age- and gender-composition of the year 1996 and add individuals' residual values to this. Third, I compare these counterfactual age- and gender-adjusted values to the unadjusted, observed values (see Figure A4). The adjusted curves can be interpreted in the following way: if the ageand gender-composition had remained unchanged at the levels of 1996, this is how cycling patterns would have evolved.

The adjusted and unadjusted values produce similar curves and lead to the same broader conclusions. In more detail, results suggest that, if age- and gender-composition had remained constant, overall contemporary cycling rates would be marginally lower than the actual observed rates. Furthermore, if the age- and gender-composition had remained unchanged, the gap between the highly educated in the cities and those that live in more rural areas would be even larger. In sum, this shows that the main findings of this paper are robust against controlling 
for the age- and gender-composition of the population. It would further be interesting to hold ethnicity/migration background constant, but such information is not available in the data.

Analysing Eastern and Western Germany separately. As noted in the main text, the Eastern German federal states are only covered by MOP starting in 1999. The main analysis combines data from all German regions and Figure A2 shows separate analyses for Eastern and Western Germany. In broad terms, patterns are similar in Eastern and Western Germany. Given that four out of five Germans live in the Western federal states, the overall picture is largely driven by the patterns in Western Germany. With a more detailed look, the regions show two relevant differences. First and foremost, in Eastern Germany cycling declined in all groups between 2008 and 2018. However, the relative evolution between the groups is the same as in the Western federal states; that is, the decline was most pronounced among people with low education in rural areas (-32.3\%) and least pronounced among people with high education in cities $(-6.1 \%)$. Therefore, cycling patterns diverge by education and residency in both regions. The second difference is that, in 2018, the group differences are somewhat more moderate in Eastern than in Western Germany.

\section{Discussion}

This paper offers a brief overview of group-specific cycling trends and compositional change in the German population over the last two decades, using representative data from 23 waves of the German Mobility Panel. Overall, cycling has increased by more than 40\% between 1996 and 2018, but this 'boom' is highly unequal. Group differences were relatively minor in the 1990s, but today, well-educated people in medium-sized and larger cities cycle two-thirds more than people in the second highest group, those with lower education in cities, and almost three times as much as people with lower education in rural areas and smaller towns. The overall increase in cycling is not only driven by altered behaviour of group members, but also by changes in the composition of the population, most notably, educational expansion. In fact, the increase in cycling during the last decade would not have occurred without educational expansion $-\mathrm{a}$ factor that should be on the radar of mobility research.

These brief analyses have limitations. The data source, the German Mobility Panel, is a unique resource because it collects detailed and reliable information about respondents' mobility behaviour and allows to trace mobility patterns over more than two decades with one coherent source. However, this contrasts with limited information on socio-demographic aspects, 
including education. The school leaving certificate is reported in all waves, but vocational training involvement is not - a limitation that these data share with the other major mobility survey, Mobility in Germany. This paper takes a macro-level perspective; that is, it focuses on societal groups rather than individuals. Inevitably, this leaves interesting questions and details untouched. For instance, future research could trace individuals from a life course perspective and study at what point people with high and low education in rural and urban settings start to differ in their mobility behaviour (see e.g., Elder, Johnson, \& Crosnoe, 2003; Janke \& Handy, 2019; Scheiner, 2014; Scheiner, Chatterjee, \& Heinen, 2016). Another interesting avenue would be to compare small-scale regional entities over time and test to what degree their level and trend in cycling is driven by the educational composition of their population and changes therein. Mobility behaviour, and cycling in particular, is highly context-dependent. Future research could therefore assess whether the patterns identified here replicate in different societies. Is the divergence in cycling by residence and education observable in other countries? Is educational expansion similarly important for changes in cycling around the world?

Cycling is a healthy and inexpensive means of transport that contributes to environmental sustainability; hence Germany's cycling 'boom' is applauded. The finding that this boom is unbalanced has relevant implications. First, people with less education have poorer health and fewer financial resources, and cycling could help with both, but the opposite is taking place, because the educational gap in cycling is large and increasing (Hendi, 2017; Mäki, Martikainen, Eikemo, Menvielle, \& Lundberg, 2013; Zajacova, Grol-Prokopczyk, \& Zimmer, 2021). Second, governments at different levels around the world are investing heavily in cyclingrelated infrastructure, in many cases redistributing resources to the detriment of drivers and in favour of cyclists (Sheldrick, Evans, \& Schliwa, 2017; Wang, 2018). If the well-educated benefit disproportionately from such changes, these policies have the unintended side-effect of reinforcing social inequalities. Third, the cycling boom is bypassing relevant parts of the population, which represents untapped potential for the contribution to sustainability goals. Suppose policy makers want to reduce such inequalities and realise the full potential of cycling for health and sustainability. In that case, they need targeted policies that reach those who stand aside from the current cycling boom: people outside the bigger cities and with less education (Braun, Rodriguez, \& Gordon-Larsen, 2019; Parra et al., 2018). Finally, the shift of the population towards higher education, which can be observed in all modern societies, is a driver behind the increase in cycling. This is good news for the future of cycling: the educational expansion will by all expectations continue and thus further boost cycling. 


\section{Bibliography}

Aldred, R., Woodcock, J., \& Goodman, A. (2016). Does more cycling mean more diversity in cycling? Transport Reviews, 36(1), 28-44. doi: 10.1080/01441647.2015.1014451

Andersen, R. (2009). Nonparametric methods for modeling nonlinearity in regression analysis. Annual Review of Sociology, 35, 67-85. doi:

10.1146/annurev.soc.34.040507.134631

Blitz, A., Busch-Geertsema, A., \& Lanzendorf, M. (2020). More cycling, less driving?

Findings of a cycle street intervention study in the Rhine-Main metropolitan region, Germany. Sustainability (Switzerland), 12(3), 9-11. doi: 10.3390/su12030805

BMVI. (2019). Cycling in Germany is booming. Retrieved 8 December 2020, from

Bundesministerium für Verkehr und Digitale Infrastruktur website:

https://www.bmvi.de/SharedDocs/EN/Dossier/Cycling/cycling-in-germany-is-booming.html Bourdieu, P. (1984). Distinction: A Social Critique of the Judgement of Taste. Cambridge, MA: Harvard University Press.

Braun, L. M., Rodriguez, D. A., \& Gordon-Larsen, P. (2019). Social (in) equity in access to cycling infrastructure: Cross-sectional associations between bike lanes and area-level sociodemographic characteristics in 22 large US cities. Journal of Transport Geography, 80, 102544.

Breen, R. (2010). Educational expansion and social mobility in the 20th century. Social Forces, 89(2), 365-388. doi: 10.1353/sof.2010.0076

Brick, C., Sherman, D. K., \& Kim, H. S. (2017). "Green to be seen" and "brown to keep down": Visibility moderates the effect of identity on pro-environmental behavior. Journal of Environmental Psychology, 51(August), 226-238.

Brondeel, R., Pannier, B., \& Chaix, B. (2016). Associations of socioeconomic status with transport-related physical activity: Combining a household travel survey and accelerometer data using random forests. Journal of Transport and Health, 3(3), 287-296. doi:

10.1016/j.jth.2016.06.002

Buehler, R., Kuhnimhof, T., Bauman, A., \& Eisenmann, C. (2019). Active travel as stable source of physical activity for one third of German adults: Evidence from longitudinal data. Transportation Research Part A: Policy and Practice, 123, 105-118.

Buehler, R., \& Pucher, J. (2021). International overview of cycling. In Cycling for Sustainable Cities (pp. 11-34). Cambridge, MA: The MIT Press.

Buehler, R., Pucher, J., \& Bauman, A. (2020). Physical activity from walking and cycling for daily travel in the United States, 2001-2017: Demogaphic, socioeconomic, and geographic variation. Journal of Transport and Health Health, 16(March), 1-14.

Carse, A., Goodman, A., Mackett, R. L., Panter, J., \& Ogilvie, D. (2013). The factors influencing car use in a cycle-friendly city: The case of Cambridge. Journal of Transport Geography, 28(April), 67-74.

Das Gupta, P. (1993). Standardization and decomposition of rates: A user's manual. US Department of Commerce, Economics and Statistics Administration, Bureau ....

Department for Transport. (2020). NTS9903: Average number of trips (trip rates) by main mode, region and rural urban classification: England. Retrieved from Ad-hoc National Travel Survey analysis website: https://www.gov.uk/government/statistical-data-sets/nts99-travel-byregion-and-area-type-of-residence

Ecke, L., Chlond, B., Magdolen, M., Hilgert, T., \& Vortisch, P. (2020). Deutsches

Mobilitätspanel (MOP)_Wissenschaftliche Begleitung und Auswertungen Bericht 2018/ 2019: Alltagsmobilität und Fahrleistung. doi: 10.5445/IR/1000105940

Elder, G. H., Johnson, M. K., \& Crosnoe, R. (2003). The emergence and development of life course theory. In J. T. Mortimer \& M. J. Shanahan (Eds.), Handbook of the Life Course (pp. 3-19). Boston, MA: Springer. doi: 10.1007/978-3-319-71812-5_38 
Elliott, R. (2013). The taste for green: The possibilities and dynamics of status differentiation through 'green' consumption. Poetics, 41(3), 294-322. doi: 10.1016/j.poetic.2013.03.003 Fan, J., \& Gijbels, I. (1996). Local Polynomial Modelling and Its Applications. London: Chapman and Hall.

Frater, J., \& Kingham, S. (2020). Adolescents and bicycling to school: Does behaviour setting/place make a difference? Journal of Transport Geography, 85(May), 102724. doi: 10.1016/j.jtrangeo.2020.102724

Friehe, T., \& Mechtel, M. (2014). Conspicuous consumption and political regimes: Evidence from East and West Germany. European Economic Review, 67(April), 62-81. doi:

10.1016/j.euroecorev.2014.01.005

Garrard, J., Rissel, C., Bauman, A., \& Giles-Corti, B. (2021). Cycling and health. In Cycling for Sustainable Cities (pp. 35-56). MIT Press Cambridge, MA.

Gehl, J. (2013). Cities for people. Washington: Island Press.

Geyer, S., Hemström, Ö., Peter, R., \& Vågerö, D. (2006). Education, income, and occupational class cannot be used interchangeably in social epidemiology. Empirical evidence against a common practice. Journal of Epidemiology and Community Health, 60(9), 804-810. doi: 10.1136/jech.2005.041319

Goebel, J., Grabka, M. M., Liebig, S., Kroh, M., Richter, D., Schröder, C., \& Schupp, J. (2019). The German Socio-Economic Panel (SOEP). Jahrbücher Für Nationalökonomie Und Statistik, 239(2), 345-360. doi: 10.1515/jbnst-2018-0022

Goel, R., Goodman, A., Aldred, R., Nakamura, R., Tatah, L., Garcia, L. M. T., ... Woodcock, J. (2021). Cycling behaviour in 17 countries across 6 continents: Levels of cycling, who cycles, for what purpose, and how far? Transport Reviews. doi:

10.1080/01441647.2021.1915898

Goodman, A., \& Aldred, R. (2018). Inequalities in utility and leisure cycling in England, and variation by local cycling prevalence. Transportation Research Part F: Traffic Psychology and Behaviour, 56, 381-391. doi: 10.1016/j.trf.2018.05.001

Gössling, S., Schröder, M., Späth, P., \& Freytag, T. (2016). Urban space distribution and sustainable transport. Transport Reviews, 36(5), 659-679. doi:

10.1080/01441647.2016.1147101

Götschi, T., Garrard, J., \& Giles-Corti, B. (2016). Cycling as a part of daily life: A review of health perspectives. Transport Reviews, 36(1), 45-71. doi: 10.1080/01441647.2015.1057877 Griskevicius, V., Tybur, J. M., \& Van den Bergh, B. (2010). Going green to be seen: Status, reputation, and conspicuous conservation. Journal of Personality and Social Psychology, 98(3), 392-404. doi: 10.1037/a0017346

Gutierrez, R. G., Linhart, J. M., \& Pitblado, J. S. (2003). From the help desk: Local polynomial regression and Stata plugins. The Stata Journal, 3(4), 412-419.

Handy, S., Heinen, E., \& Krizek, K. J. (2012). Cycling in Small Cities. In City Cycling (pp. 257-286). doi: 10.7551/mitpress/9434.003.0015

Hendi, A. S. (2017). Trends in education-specific life expectancy, data quality, and shifting education distributions: A note on recent research. Demography, 54(3), 1203-1213. doi: 10.1007/s13524-017-0574-2

Holz-Rau, C., \& Scheiner, J. (2019). Land-use and transport planning - A field of complex cause-impact relationships. Thoughts on transport growth, greenhouse gas emissions and the built environment. Transport Policy, 74(October 2018), 127-137. doi:

10.1016/j.tranpol.2018.12.004

Horton, D., Rosen, P., \& Cox, P. (2016). Cycling and Society. London: Routledge.

Hudde, A. (2022). Educational Differences in Cycling: Evidence from German Cities. Sociology, 1-21. doi: 10.1177/00380385211063366

Huisman, M., Kunst, A. E., \& Mackenbach, J. P. (2005). Inequalities in the prevalence of smoking in the European Union: Comparing education and income. Preventive Medicine, 
40(6), 756-764. doi: 10.1016/j.ypmed.2004.09.022

Jacob, N., Munford, L., Rice, N., \& Roberts, J. (2020). Does commuting mode choice impact health? Health Economics, (September). doi: 10.1002/hec.4184

Janke, J., \& Handy, S. (2019). How life course events trigger changes in bicycling attitudes and behavior: Insights into causality. Travel Behaviour and Society, 16, 31-41. doi: 10.1016/j.tbs.2019.03.004

Kennedy, E. H., \& Horne, C. (2019). Do green behaviors earn social status? Socius: Sociological Research for a Dynamic World, 5, 1-9. doi: 10.1177/2378023119836330

Kirschner, F., \& Lanzendorf, M. (2020). Support for innovative on-street parking policies: Empirical evidence from an urban neighborhood. Journal of Transport Geography, 85(March), 102726. doi: 10.1016/j.jtrangeo.2020.102726

Knies, G., \& Spiess, C. K. (2007). Regional Data in the German Socio-Economic Panel Study (SOEP).

Kreyenfeld, M., \& Konietzka, D. (2017). Alltagsmobilität und Lebenslauf. In Statistisches Bundesamt (Ed.), Wie die Zeit vergeht. Analysen zur Zeitverwendung in Deutschland. Beiträge zur Ergebniskonferenz der Zeitverwendungserhebung 2012/2013 am 5./6. Oktober 2016 in Wiesbaden (pp. 163-178). Wiesbaden.

Kroesen, M., \& Handy, S. (2014). The relation between bicycle commuting and non-work cycling: Results from a mobility panel. Transportation, 41(3), 507-527. doi: 10.1007/s11116013-9491-4

Larsen, J. (2017). The making of a pro-cycling city: Social practices and bicycle mobilities. Environment and Planning A, 49(4), 876-892. doi: 10.1177/0308518X16682732

Lutz, W., \& Samir, K. C. (2011). Global human capital: Integrating education and population. Science, 333(6042), 587-592.

Mäki, N., Martikainen, P., Eikemo, T., Menvielle, G., \& Lundberg, O. (2013). Educational differences in disability-free life expectancy: A comparative study of long-standing activity limitation in eight European countries. Social Science and Medicine, 94(October), 1-8. doi: 10.1016/j.socscimed.2013.06.009

Martin, A., Goryakin, Y., \& Suhrcke, M. (2014). Does active commuting improve psychological wellbeing? Longitudinal evidence from eighteen waves of the British Household Panel Survey. Preventive Medicine, 69(December), 296-303. doi: 10.1016/j.ypmed.2014.08.023

Moav, O., \& Neeman, Z. (2012). Saving rates and poverty: The role of conspicuous consumption and human capital. Economic Journal, 122(563), 933-956. doi: 10.1111/j.14680297.2012.02516.x

Nichols, A. (2007). Causal inference with observational data. The Stata Journal, 7(4), 507541. doi: 10.1177/1536867x0800700403

Nobis, C. (2019). Mobilität in Deutschland - MiD. Analysen zum Radverkehr und Fußverkehr. Berlin, Germany.

Oja, P., Titze, S., Bauman, A., de Geus, B., Krenn, P., Reger-Nash, B., \& Kohlberger, T. (2011). Health benefits of cycling: A systematic review. Scandinavian Journal of Medicine and Science in Sports, 21(4), 496-509. doi: 10.1111/j.1600-0838.2011.01299.x

Olafsson, A. S., Nielsen, T. S., \& Carstensen, T. A. (2016). Cycling in multimodal transport behaviours: Exploring modality styles in the Danish population. Journal of Transport Geography, 52, 123-130. doi: 10.1016/j.jtrangeo.2016.03.010

Pampel, F. C., Krueger, P. M., \& Denney, J. T. (2010). Socioeconomic disparities in health behaviors. Annual Review of Sociology, 36, 349-370. doi:

10.1146/annurev.soc.012809.102529

Parra, D. C., Gomez, L. F., Pinzon, J. D., Brownson, R. C., \& Millett, C. (2018). Equity in cycle lane networks: Examination of the distribution of the cycle lane network by

socioeconomic index in Bogotá, Colombia. Cities \& Health, 2(1), 60-68. doi: 


\subsection{0/23748834.2018.1507068}

Prognos AG. (2020). Bilanzierung des Nationalen Radverkehrsplan 2020. Berlin.

Pucher, J., \& Buehler, R. (2006). Why Canadians cycle more than Americans: A comparative analysis of bicycling trends and policies. Transport Policy, 13(3), 265-279. doi:

10.1016/j.tranpol.2005.11.001

Pucher, J., Parkin, J., \& de Lanversin, E. (2021). Cycling in New York, London, and Paris. In Cycling for Sustainable Cities (pp. 321-346). MIT Press Cambridge, MA.

Rachele, J. N., Kavanagh, A. M., Badland, H., Giles-Corti, B., Washington, S., \& Turrell, G. (2015). Associations between individual socioeconomic position, neighbourhood disadvantage and transport mode: Baseline results from the HABITAT multilevel study.

Journal of Epidemiology and Community Health, 69(12), 1217-1223.

Reimer, D. (2013). Kontexteffekte und soziale Ungleichheit beim Übergang von der Schule zur Hochschule. In R. Becker \& A. Schulze (Eds.), Bildungskontexte: Strukturelle Voraussetzungen und Ursachen ungleicher Bildungschancen (pp. 405-429). Wiesbaden: Springer Fachmedien Wiesbaden. doi: 10.1007/978-3-531-18985-7_14

Scheepers, E., Wendel-Vos, W., van Kempen, E., Panis, L. I., Maas, J., Stipdonk, H., ... Schuit, J. (2013). Personal and environmental characteristics associated with choice of active transport modes versus car use for different trip purposes of trips up to 7.5 kilometers in The Netherlands. PLoS ONE, 8(9), 1-10. doi: 10.1371/journal.pone.0073105

Scheiner, J. (2014). Gendered key events in the life course: Effects on changes in travel mode choice over time. Journal of Transport Geography, 37(May), 47-60. doi:

10.1016/j.jtrangeo.2014.04.007

Scheiner, J., Chatterjee, K., \& Heinen, E. (2016). Key events and multimodality: A life course approach. Transportation Research Part A: Policy and Practice, 91, 148-165. doi: 10.1016/j.tra.2016.06.028

Schwanen, T., Dijst, M., \& Dieleman, F. M. (2004). Policies for urban form and their impact on travel: The Netherlands experience. Urban Studies, 41(3), 579-603. doi:

10.1080/0042098042000178690

Sheldrick, A., Evans, J., \& Schliwa, G. (2017). Policy learning and sustainable urban transitions: Mobilising Berlin's cycling renaissance. Urban Studies, 54(12), 2739-2762. Spellerberg, A. (1996). Soziale Differenzierung durch Lebensstile: Eine empirische Untersuchung zur Lebensqualität in West-und Ostdeutschland. Berlin: edition sigma. Steinbach, R., Green, J., Datta, J., \& Edwards, P. (2011). Cycling and the city: A case study of how gendered, ethnic and class identities can shape healthy transport choices. Social Science and Medicine, 72(7), 1123-1130.

Turek, K., \& Leopold, T. (2021). The comparative panel file: Harmonized household panel surveys from seven countries. European Sociological Review, 37(3), 505-523. doi: 10.1093/esr/jcab006

Van de Werfhorst, H. G., \& Mijs, J. J. B. (2010). Achievement inequality and the institutional structure of educational systems: A comparative perspective. Annual Review of Sociology, 36, $407-428$.

Wang, L. (2018). Barriers to implementing pro-cycling policies: A case study of Hamburg. Sustainability, 10(11), 4196.

World Health Organization. (2019). Global action plan on physical activity 2018-2030: More active people for a healthier world. Geneva: World Health Organization.

Zajacova, A., Grol-Prokopczyk, H., \& Zimmer, Z. (2021). Pain trends among American adults, 2002-2018: Patterns, disparities, and correlates. Demography, 58(2), 711-738. doi: 10.1215/00703370-8977691

Ziefle, A. (2016). Persistent educational advantage across three generations: Empirical evidence for Germany. Sociological Science, 3, 1077-1102. doi: 10.15195/v3.a47 


\section{Appendix}

(A) Average minutes of cycling / week

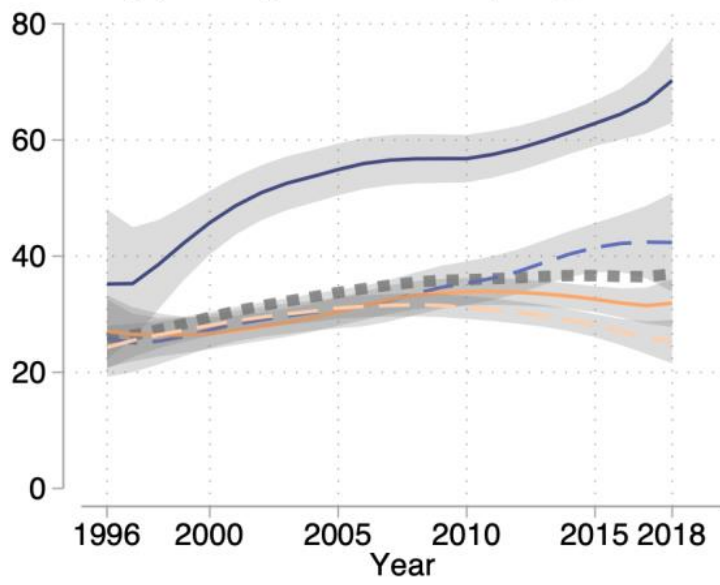

(B) Average minutes of cycling / week

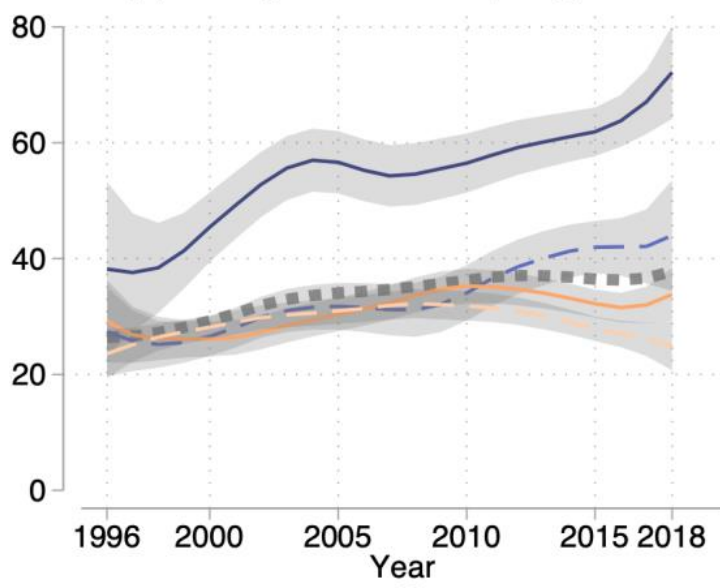

(C) Average minutes of cycling / week

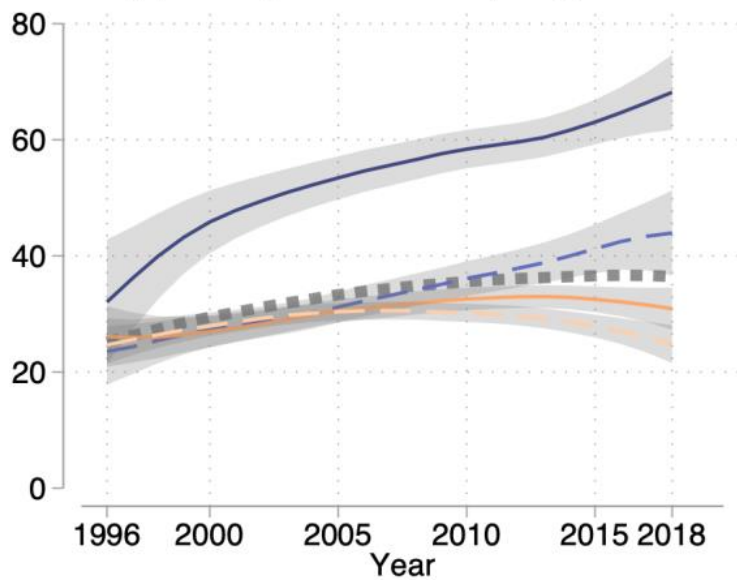

(A) At least 150 mins of cycling / week

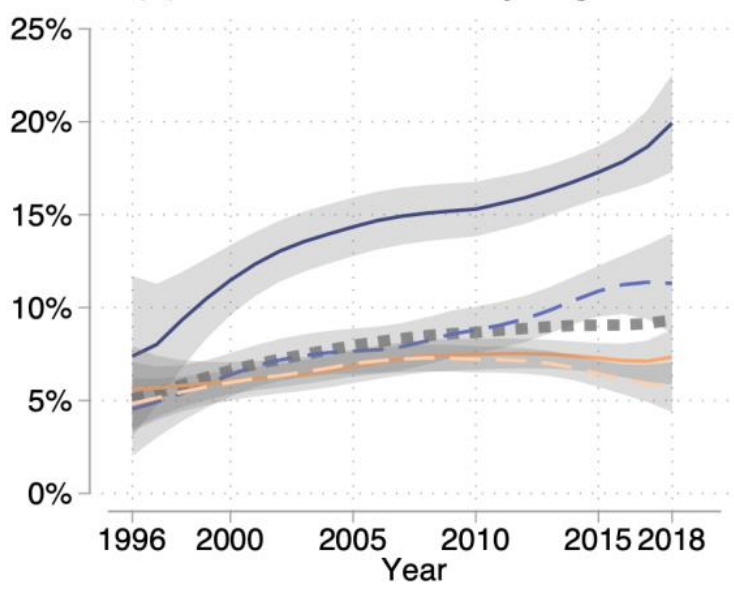

(B) At least 150 mins of cycling / week

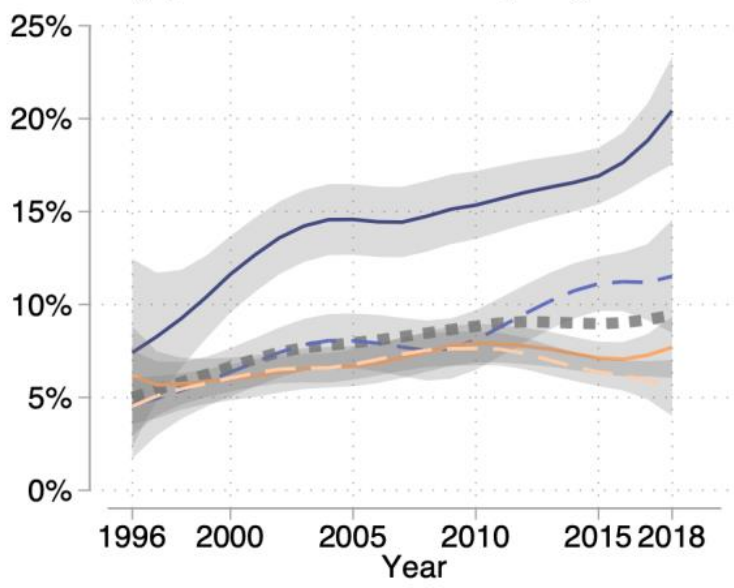

(C) At least 150 mins of cycling / week

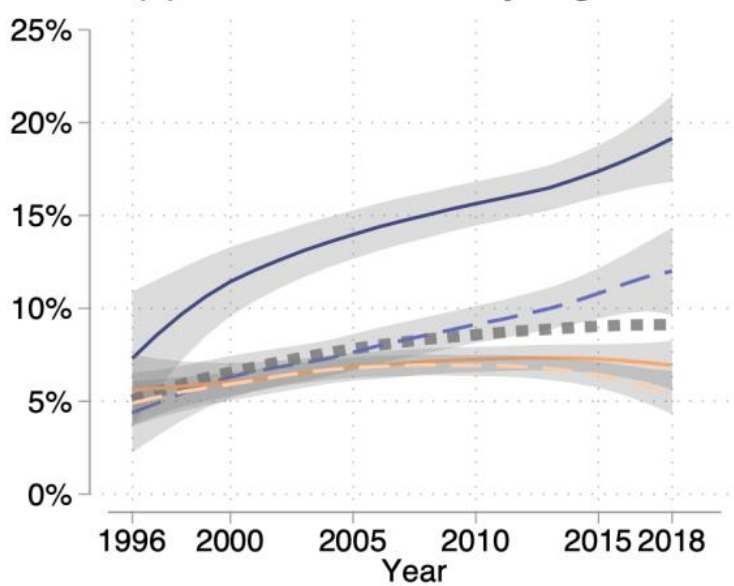

" I. I All groups combined - Medium-sized \& larger cities, - . Medium-sized \& larger cities, Rural \& smaller towns, _- Rural \& smaller towns, high education - low education

Fig A1: Comparing different bandwidths for smoothing the data. (A) denotes the bandwidth of the main analyses, (B) a smaller bandwidth, and (C) a larger bandwidth. 

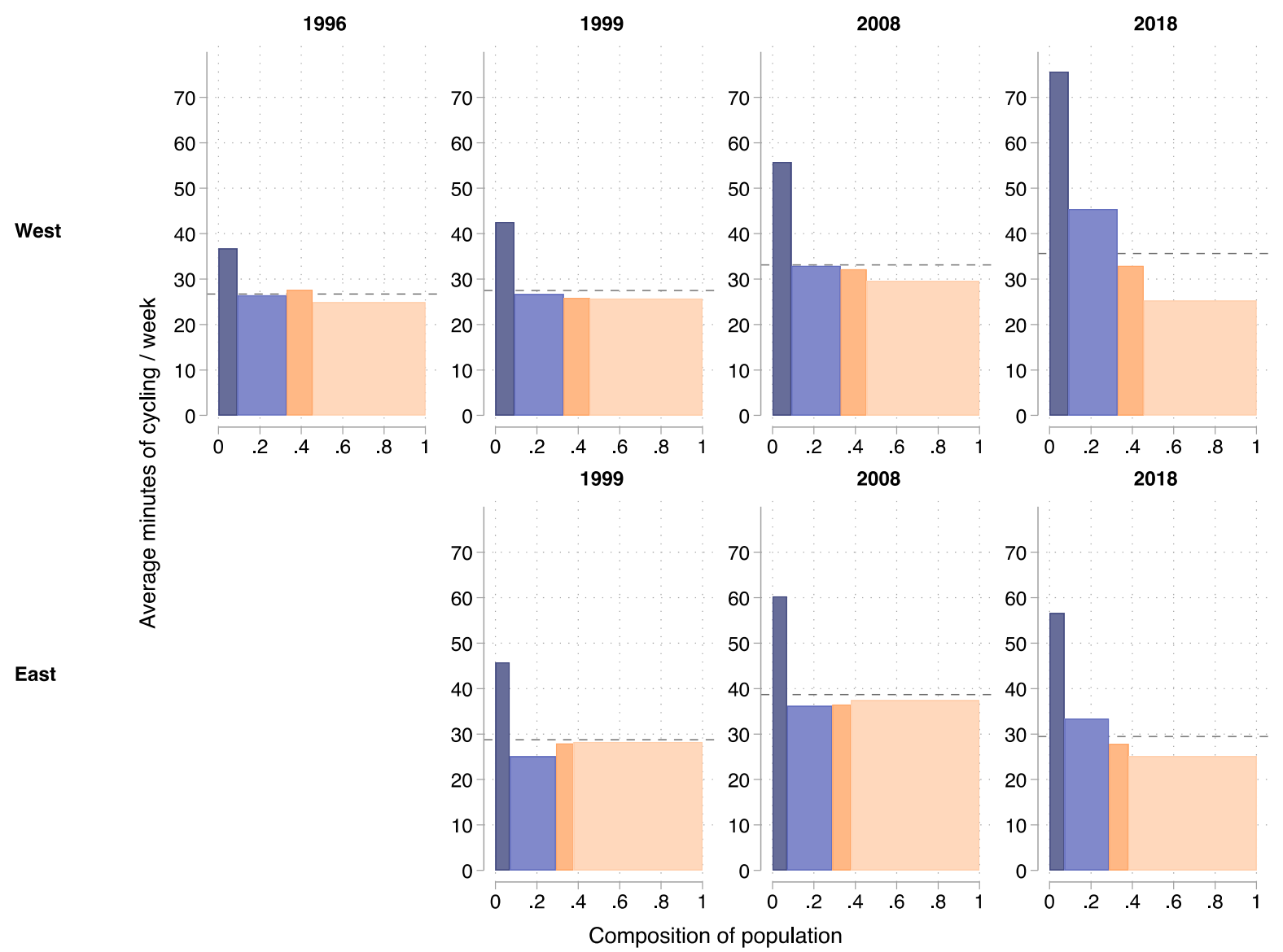

Medium-sized \& larger
cities, high education $\quad \begin{aligned} & \text { Medium-sized \& larger } \\ & \text { cities, low education }\end{aligned}$ cities, high education

Rural \& smaller towns, high education

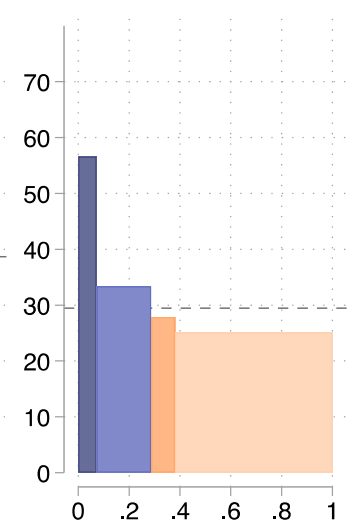

Fig A2: Comparing Eastern and Western Germany. Data for Eastern Germany is only available for 1999 onwards. 


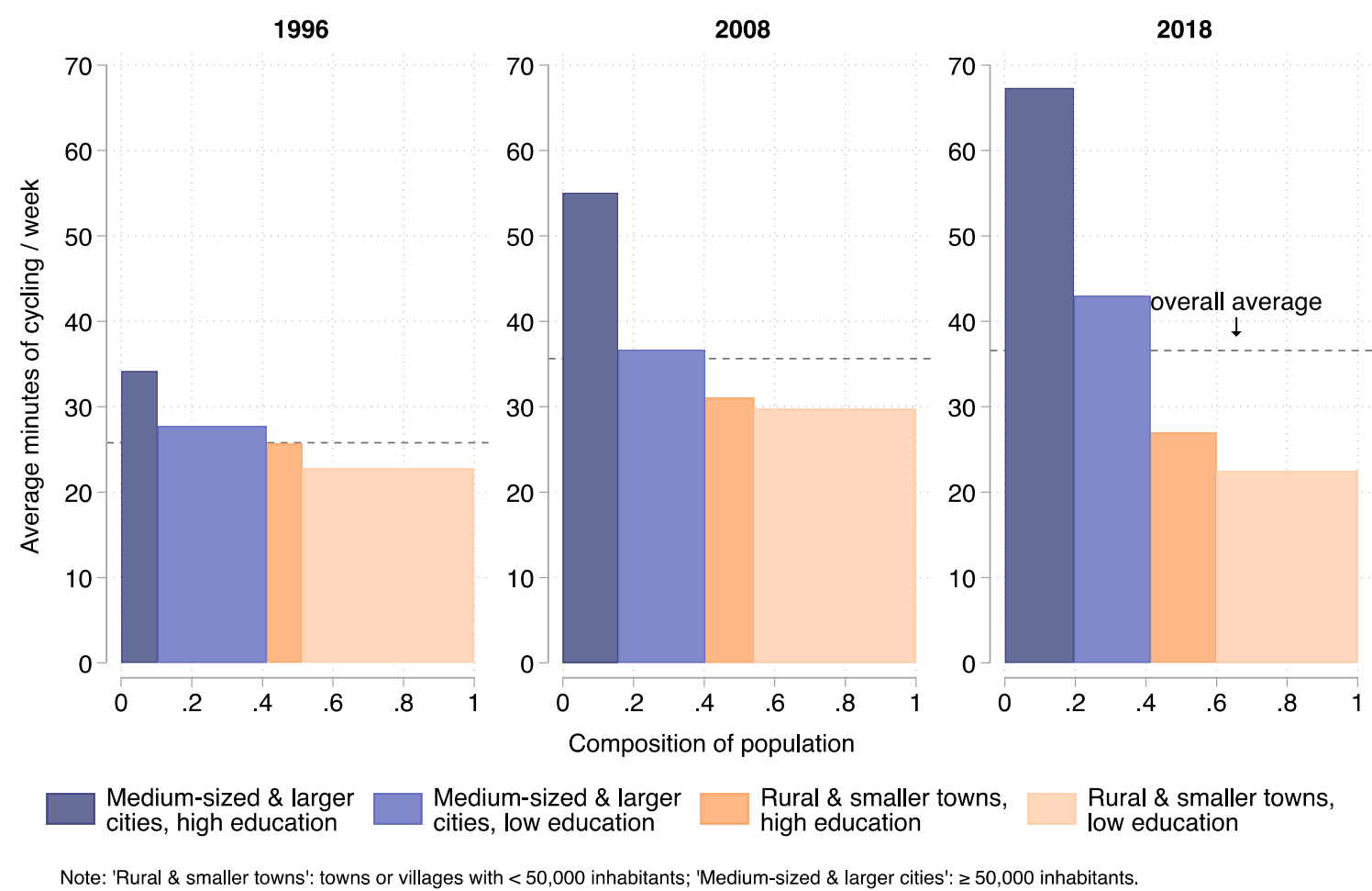

Fig A3: Changing the cut-off value for the distinction between 'medium-sized and larger cities' and ' rural aras and smaller towns' from 100,000 to 50,000 inhabitants.

Table A1. Average age and share of women by location and education. Data source: German Socio-Economic Panel (SOEP). Survey weights are applied.

\begin{tabular}{|c|c|c|c|c|c|c|c|c|c|c|}
\hline \multirow[t]{2}{*}{ Year } & \multirow{2}{*}{\multicolumn{2}{|c|}{$\begin{array}{c}\text { All groups } \\
\varnothing \text { age } \% \text { women }\end{array}$}} & \multicolumn{2}{|c|}{$\begin{array}{r}\text { Medium-sized \& } \\
\text { larger cities, } \\
\text { high education }\end{array}$} & \multicolumn{2}{|c|}{$\begin{array}{r}\text { Medium-sized \& } \\
\text { larger cities, } \\
\text { low education }\end{array}$} & \multicolumn{2}{|c|}{$\begin{array}{r}\text { Rural \& smaller } \\
\text { towns, high education }\end{array}$} & \multicolumn{2}{|c|}{$\begin{array}{l}\text { Rural \& smaller } \\
\text { towns, low education }\end{array}$} \\
\hline & & & $\varnothing$ age & $\%$ women & $\varnothing$ age & $\%$ women & $\varnothing$ age & $\%$ women & $\varnothing$ age & $\%$ women \\
\hline 1996 & 43.8 & $49.9 \%$ & 39.9 & $43.3 \%$ & 45.5 & $52.7 \%$ & 39.8 & $39.3 \%$ & 44.5 & $51.8 \%$ \\
\hline 1997 & 43.9 & $49.6 \%$ & 39.5 & $42.8 \%$ & 46.0 & $52.4 \%$ & 39.8 & $39.0 \%$ & 44.6 & $51.7 \%$ \\
\hline 1998 & 44.2 & $49.7 \%$ & 40.4 & $44.6 \%$ & 46.2 & $52.1 \%$ & 40.2 & $40.8 \%$ & 44.9 & $51.5 \%$ \\
\hline 1999 & 44.4 & $49.5 \%$ & 40.0 & $44.7 \%$ & 46.6 & $51.4 \%$ & 40.9 & $41.1 \%$ & 45.1 & $51.5 \%$ \\
\hline 2000 & 44.4 & $49.6 \%$ & 40.4 & $45.1 \%$ & 46.2 & $51.9 \%$ & 41.6 & $41.6 \%$ & 45.2 & $51.6 \%$ \\
\hline 2001 & 44.5 & $49.5 \%$ & 40.6 & $46.2 \%$ & 46.4 & $51.3 \%$ & 42.0 & $41.6 \%$ & 45.2 & $51.5 \%$ \\
\hline 2002 & 44.7 & $49.3 \%$ & 40.9 & $45.4 \%$ & 46.4 & $51.1 \%$ & 42.1 & $42.5 \%$ & 45.4 & $51.2 \%$ \\
\hline 2003 & 44.6 & $49.5 \%$ & 40.9 & $46.3 \%$ & 46.2 & $51.0 \%$ & 41.9 & $44.1 \%$ & 45.4 & $51.1 \%$ \\
\hline 2004 & 44.6 & $49.2 \%$ & 40.6 & $45.0 \%$ & 46.4 & $50.6 \%$ & 42.1 & $44.9 \%$ & 45.5 & $50.8 \%$ \\
\hline 2005 & 44.1 & $49.6 \%$ & 40.0 & $46.5 \%$ & 46.2 & $49.5 \%$ & 42.0 & $47.2 \%$ & 44.9 & $51.1 \%$ \\
\hline 2006 & 44.3 & $49.3 \%$ & 40.0 & $46.5 \%$ & 46.3 & $49.5 \%$ & 42.3 & $46.8 \%$ & 45.1 & $50.6 \%$ \\
\hline 2007 & 44.3 & $49.6 \%$ & 40.2 & $47.9 \%$ & 46.3 & $49.1 \%$ & 42.3 & $46.9 \%$ & 45.3 & $51.0 \%$ \\
\hline 2008 & 44.5 & $49.4 \%$ & 40.2 & $47.0 \%$ & 46.3 & $49.0 \%$ & 42.4 & $45.9 \%$ & 45.5 & $51.1 \%$ \\
\hline 2009 & 44.6 & $49.3 \%$ & 40.3 & $47.8 \%$ & 46.6 & $48.6 \%$ & 42.4 & $46.7 \%$ & 45.8 & $50.9 \%$ \\
\hline 2010 & 45.0 & $49.2 \%$ & 40.9 & $46.1 \%$ & 46.8 & $50.2 \%$ & 42.7 & $48.6 \%$ & 46.4 & $50.0 \%$ \\
\hline 2011 & 45.2 & $49.7 \%$ & 40.8 & $47.6 \%$ & 46.8 & $50.2 \%$ & 43.0 & $48.6 \%$ & 46.6 & $50.5 \%$ \\
\hline 2012 & 45.3 & $49.6 \%$ & 40.9 & $47.5 \%$ & 46.7 & $50.7 \%$ & 43.2 & $49.0 \%$ & 46.8 & $50.0 \%$ \\
\hline 2013 & 45.4 & $50.0 \%$ & 41.0 & $48.7 \%$ & 46.6 & $50.4 \%$ & 43.3 & $48.1 \%$ & 47.2 & $50.9 \%$ \\
\hline 2014 & 45.5 & $50.0 \%$ & 41.2 & $49.1 \%$ & 46.9 & $49.2 \%$ & 43.2 & $49.2 \%$ & 47.4 & $51.0 \%$ \\
\hline 2015 & 45.6 & $49.8 \%$ & 41.3 & $48.4 \%$ & 47.0 & $48.6 \%$ & 43.4 & $49.9 \%$ & 47.5 & $50.6 \%$ \\
\hline 2016 & 45.6 & $49.4 \%$ & 41.0 & $49.2 \%$ & 46.7 & $46.1 \%$ & 43.7 & $49.3 \%$ & 47.6 & $50.6 \%$ \\
\hline 2017 & 45.6 & $49.1 \%$ & 41.2 & $48.5 \%$ & 46.7 & $48.4 \%$ & 43.9 & $48.9 \%$ & 47.5 & $49.6 \%$ \\
\hline 2018 & 46.0 & $49.0 \%$ & 41.7 & $46.6 \%$ & 46.9 & $48.8 \%$ & 44.3 & $49.0 \%$ & 47.9 & $50.0 \%$ \\
\hline
\end{tabular}




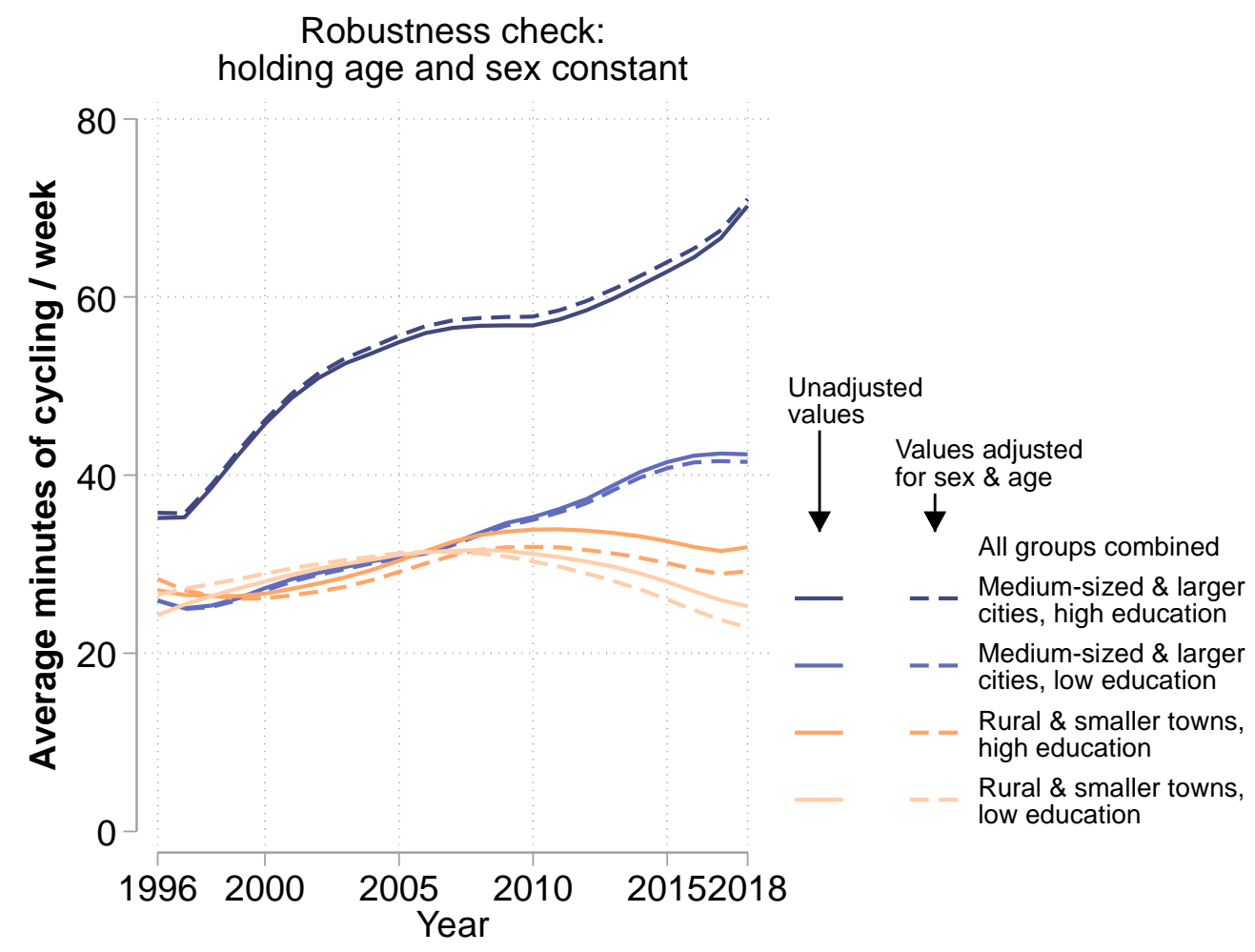

Fig A4: Adjusting for changes in the gender- and age-composition (comparing observed or unadjusted behavioural changes to the counterfactual of a gender- and age-composition that remains constant at the values of 1996 [adjusted values]). 